\title{
Usage of Information and Communication Technologies in Teaching English
}

\author{
Nargiza Babaniyazova, Nukus State pedagogical institute Republic of Uzbekistan \\ Kizlargul Kalimbetova, Nukus State pedagogical institute Republic of Uzbekistan
}

\begin{abstract}
The article presents the usage of information and communication technologies (ICT) in teaching foreign language. Also, the article deals with the essence of information and communication technologies, their role in teaching foreign language in conditions of modernization of education, a classification of using for new information technologies in teaching foreign language. The conclusion is made about the expediency of using ICT to improve the quality of students' knowledge, to increase the interest for the lessons
\end{abstract}

Keywords: Educational Standards, information communication technologies, English lesson, foreign language, modernization, education, ICT facilities, teaching English, teacher.

$\begin{array}{lll}\text { Received: } 14.12 .2020 & \text { Accepted: } 10.01 .2021 & \text { Published: 04.02.2021 }\end{array}$

\section{INTRODUCTION}

In the modern world, education plays an important role in the society. Moreover, the requirements for the education system and for the knowledge of student have changed. Based on the realities of today's life, the skills of schoolchild of the 21st century are identified: high professionalism in a certain area, the ability to present and present oneself, knowledge of psychology, the ability to apply knowledge in the condition of real life. Such competencies in the education system are developed through the use of innovative pedagogical technologies.

Information and communication technologies (ICT) can be distinguished among all educational technologies. We believe that the use of ICT in educational activities contributes to the achievement of meta-subject educational outcomes. In the Standard, meta-subject educational outcomes are defined as "mastered interdisciplinary concepts of students and universal educational actions (regulatory, cognitive, communicative), the ability to use them in educational, cognitive and social practice, independence of planning and implementation educational activities and the organization of educational cooperation with teachers and peers, building an individual educational trajectory" [2].

The use of multimedia in English lessons helps to implement of personality-oriented approach to learning, provides individualization and differentiation, taking into account the characteristics of children, their interests and inclinations.

However, the prospects for the usage of "information and communication technologies in the educational activities of the school depend on the pedagogical factors, these are, on the level of the teacher's ICT competence, his/her general erudition, his/her readiness and ability to integrate ICT into educational activities"[4]. Therefore, a modern teacher needs to improve constantly the level of professional qualifications, follow all the innovations in the field of education, attend seminars, conferences, master classes and round tables. One of the forms of increasing the teacher's ICT competence can be participation in the creative laboratory.

The use of ICT in the study of foreign languages promotes:

- development of creative possibilities and abilities of students;

- creating conditions for self-education of students in the areas of interest to them;

- increasing the level of using visibility in the lesson;

- improving the productivity of the lesson;

- establishment of interdisciplinary connections;

- the acquisition of real experience of intercultural education;

- enriching students' knowledge about history and culture of other countries of the target language;

- developing the ability to navigate in modern foreign language environment [5].

In a modern system education, a situation has developed when the well-established methods, techniques and forms of teaching require reflection, correction and new pedagogical solutions. This is primarily due to the widespread introduction and widespread usage of information and communication technologies. Similar technologies are actively used to transfer information and ensuring interaction 
between teacher and student in modern systems of opening and distance education. Modern teacher must have not only knowledge of ICT, but also to be an expert in their application in professional activity.

\section{LITERATURE REVIEW}

The usage of new information technologies in teaching is one of the most important aspects of improving and optimizing educational process, enrichment of the arsenal of methodological tools and techniques that allow you to diversify the forms of work and make the process of teaching a foreign language interesting and memorable for students.

In modern science, there are many different approaches to the definition of the term "information and communication technologies". According to the dictionary

pedagogical use (under the editorship of L.M. Luzina), information and communication technology (ICT) is a set of tools and methods for transforming information data to obtain information of a new quality (information product) [1].

In modern sources, information and communication technologies represent a wide range of digital technologies used for the creation, transmission and distribution of information and the provision of services (computer equipment, software, cellular, electronic mail, cellular and satellite technologies, wireless and cable networks, multimedia, and the Internet) [2].

According to G.K Selevko, "pedagogical (educational) technology is a functional system of all components of the pedagogical process, is built on a scientific basis, programmed on time and space, leading are intended to results". By methods and ways of teaching and upbringing, he distinguishes the following pedagogical technologies: dogmatic, reproductive, explanatory and illustrative, coercion, free choice, programmed education, problematic, search, research, developmental, self-development, group, collective, informational, dialogical, communicative, interactive, game, labor, creative, art technologies, etc $[1,12]$.

In the work of G.F Polushkina - "Assessment of meta-subject results of education in the foreign language in basic school", it is noted that the results of meta-subject - "mastering the basic educational program of basic general education in the foreign language shows: the ability to determine learning goals independently, activities, the ability to generalize, establish analogies, classify, establish causal relationships, build logical reasoning, draw conclusions "[3,11].

\section{RESEARCH METHODOLOGY}

Teaching foreign language with ICT is an effective pedagogical tool for studying foreign language, culture of foreign coutry and developing communication skills. It should be noted that the use of ICT contributes to the acceleration of the learning process, the growth of students' interest to the subject, improves the quality of the assimilation of the material, makes it possible to individualize the learning process and make it possible to avoid the subjectivity of assessment. Foreign language lessons with using ICT are distinguished by diversity, increased interest and efficiency of students in a foreign language.

The modern educational paradigm, based on computer teaching aids, is based not only the transfer of ready-made knowledge, skills and abilities to schoolchildren, but also the imparting of self-education skills to the student. At the same time, the work of students in the lesson is in the nature of communication with the teacher, mediated with the help of interactive computer programs and audiovisual means.

The most frequently used ICT tools in the educational process include:

- electronic textbooks and manuals that demonstrated with using a computer and a multimedia projector

- $\quad$ electronic encyclopedias and reference books

- $\quad$ simulators and testing programs

- $\quad$ educational resources of the Internet

- $\quad$ DVD and CD discs with pictures and illustrations

- $\quad$ video and audio equipment

- $\quad$ multimedia presentations

- $\quad$ research works and projects.

Methodologists distinguish several classifications of ICT tools. In accordance with the first classification, all ICT tools that used in the education system can be divided into two types:

1) hardware (computer, printer, scanner, camera, video camera, audio and video recorder, etc.)

2) software (electronic textbooks, simulators, test environments, information sites, Internet search engines, etc.). 
The current breakthrough in the field of ICT forces us to reconsider the issues of organizing information support for cognitive activity. Thus, the second classification of ICT tools allows us to consider the possibilities of using information technologies in educational activities:

- to search from literatures, on the Internet with using browsers such as InternetExplorer, MozillaFirefox, etc.;

- $\quad$ various search engines (Yandex.ru, Rambler.ru, Mail.ru, Google.ru, Yahoo.com, etc.);

- $\quad$ communication (Internet, email, ICQ, Skype, MailAgent, etc.);

- $\quad$ work with it (abstracting, note-taking, annotating, quoting, etc.);

- $\quad$ storing and accumulating information (CDs, DVDs, Flash disks);

- $\quad$ automatic translation of texts using translation programs (PROMTXT) and electronic dictionaries (AbbyLingvo7.0);

- $\quad$ working with texts with using the basic Microsoft Office software package;

For example, Microsoft Word allows to create and edit texts with graphic design; Microsoft PowerPoint allows to create presentation slides for a more colorful presentation of the material; Microsoft Excel perform calculations, analyze and visualize data, and work with lists in tables and on web pages; Microsoft Office Publisher lets make and modify booklets, brochures, and etc. For processing and reproducing graphics and sound (Microsoft Media Player, WinAmp, WinDVD, zplayer, programs for viewing images ACDSee, PhotoShop, CorelDraw, programs for creating diagrams, drawings and graphics Visio), etc.;

The listed ICT tools create favorable opportunities in English lessons and for organizing students' independent work. They help to use computer technologies both for studying certain topics and for selfcontrol of the knowledge gained. Modern programs require the student to concentrate, focus, and stress memory. Not every student is able to work in this mode. Psychological characteristics of character, the type of perception of the child become the reason for failure. At the same time, modern requirements for the level of education do not allow to reduce the amount of information required by the student to master the topic of the lesson.

However, when organizing a lesson using computer programs, information is provided to students in a colorfully designed, using animation effects, in the form of text, diagrams, graphics, drawings. All this, in the opinion of modern didactics, makes it possible to more clearly and easily explain the educational material.

\section{ANALYSIS AND RESULT}

As mentioned above, information and communication technologies acquire great importance: they develop motivation in English lessons, provide flexibility in the management of educational activities, help in choosing the best training option, and participate in monitoring the activities of students.

Using information resources of the Internet, it is possible, by integrating them into the educational process, to solve effectively a number of didactic tasks, in particular, in the English lessons.

a) to form skills and abilities of reading, directly using materials of the network of varying degrees of complexity;

b) improve the skills of perception of a foreign language, aural speech based on authentic audio network texts;

c) improve the skills of monologue and dialogical statements based on problematic discussion;

d) improve the skills of writing, individually, in writing, composing answers to partners, participating in the preparation of abstracts, essays, other types of correspondence in the process of joint activities of partners [6].

e) improving lexical and grammatical skills through training with the help of programs, games, tests

Classic and integrated lessons, that accompanied by multimedia presentations, online tests and software products allow students to deepen knowledge, as they say in English proverb - "I heard and forgot, I saw and remembered", The studies by German scientists have shown that a person remembers only $10 \%$ of what he reads, $20 \%$ of what he hears, $30 \%$ of what he sees; $50-70 \%$ are remembered when participating in group discussions, $80 \%$ - when they independently identify and formulate problems. When the student is directly involved in real activity, in self-production problems, development and decision-making, formulation conclusions and forecasts, he memorizes and assimilates the material by $90 \%$ [7].

The English teachers and professors takes an active part in the work of creative laboratories. For example, from 2016 to 2019, such creative laboratories were organized as "Management of the process of introducing electronic teaching aids into the practice of a modern teacher", "Designing work programs of basic general education in the conditions of implementation", "Simulator for preparing for the Unified 
State Exam in English. Listening". The purpose of such laboratories was to improve the methodological and educational competence of teachers [7].

During the work of creative laboratories, through the joint efforts of teachers, various possibilities of information and communication technologies were considered, studied and methodological recommendations for their use in educational activities were created. During the practice in the classroom, teachers learn to create effective presentations, flash animations, joint presentations on Google search services, interactive text users in the MyTest X program, master the technology of creating a professional website of teachers. Laboratory participants achieve the opportunity to get acquainted with the experience of colleagues and adopt it. We consider this form of increasing professional competence of teachers are the most effective and appropriate. The laboratory participants are unanimous in the opinion that the most frequently that used as ICT tools in educational activities are interactive boards, electronic encyclopedias and reference books, simulators and testing programs, educational Internet resources, interactive maps and atlases.

In this article, we propose to consider in more detail some of them. The use of Internet resources is not less importance for improving the quality of students' knowledge in English lessons. Reasonable usage of such resources contributes to: the formation of reading skills and abilities; improving the writing skills of schoolchildren; developing listening skills based on authentic sound texts by native speakers; improving the ability to monologue and dialogical statements based on problematic discussion of materials on the Internet; replenishment of the vocabulary of students; formation of stable motivation among schoolchildren to learn English; expanding their horizons; establishing and maintaining intercultural ties with peers from other countries.

1. The Quizlet.com service provides the ability to create interactive learning cards (flashcards) and learning games. Therefore, the author of the article actively uses this service in English lessons to train spelling, translation and definition of the meaning of words. In addition, the service is used actively in English lessons.

2. LearningApps.org. This interactive resource allows you to develop tasks in different modes: "Puzzles", "Set the sequence", "Quiz with the choice of the correct answer", etc.

3. Another useful resource for English lessons is the Prezi.com web service. Teachers can create interactive multimedia presentations with a non-linear structure, which allow you to focus on a specific fragment without switching slides. The technology of creating such presentations is easily mastered by students, using them when preparing mini-projects, reports on a specific topic.

Currently, educational organizations are well equipped with technical training aids. In our opinion, an interactive whiteboard is an effective tool that helps to increase the cognitive activity of schoolchildren. Interactive whiteboards allow not only "to present audiovisual information using various multimedia resources, but also contribute to the activation of educational and cognitive activities of students through the interaction of participants in educational relations during an interactive dialogue, realizing through the use of various types of feedback, independence in the choice of studying educational information, volume and level of complexity, time and the pace of work, the creation of creative educational product in the process of active transformation of educational information"[5]. The use of interactive whiteboards in educational activities makes it possible to combine information and communication and traditional techniques, forms of organization of educational activities. Also, thanks to the tools an interactive whiteboard, every action or reaction of the participants in the interaction is reflected on the screen, available for consideration, understanding and discussion by all participants in educational activities. The result is an increase in the productivity of the learning process by reducing the time for individual interaction with the student.

Based on work experience, we can state the fact that the use of interactive whiteboards at an early stage of teaching foreign languages allows to provide real visibility and situational awareness, creative work of students, the joy of learning with the successful completion of tasks, hence the development of thinking and situational speech. Also in the classroom in elementary school we actively use the multimedia application for the teaching materials Spotlight 2-4. It is extremely interesting for students to work at the interactive whiteboard: to select matches, collect puzzles, make inscriptions, solve scan words [8].

We can say with confidence that the quality of students' knowledge when using interactive whiteboard tools at this level is higher than in its absence. Students remember so well vivid images of textbook heroes, short cartoons that dedicated to various modules, that then, they are often recalled and asked to work with the application. Working with situational dialogues, schoolchildren repeatedly listen to and reproduce lexical units, it is a holistic approach, implementation to learn a foreign language. At the basic general education level, presentations are made on the most interesting topics of the textbook. Students prepare not only presentations, but also they simultaneously learn to construct monologue statements, which allows them to work with oral speech. 
At the senior level of education, in grades 9-11, the interactive whiteboard is often used as a screen for displaying information. Listening tasks, grammar and vocabulary exercises and speaking tasks are displayed on the screen and practiced by all students both in the classroom and at home. The multimedia simulators are created in the Microsoft Office Power Point program, and this program is actively used [9].

One of the urgent problems of modern methods of teaching foreign languages is the organization of teaching children of different ages using game technologies. The urgency of this problem is caused by a number of factors.

The first, the intensification of the educational process sets the task search for means of maintaining students' interest in the material being studied and intensifying their activities throughout the whole lesson. An effective means of solving this problem are educational games.

The second, one of the most important problems of teaching a foreign language is learning oral speech, which creates conditions for the disclosure of the communicative function of the language and allows to bring the learning process closer to the conditions of real learning, which increases motivation to learn a foreign language. The involvement of students in oral communication can be successfully carried out in the process of play activities.

On this way, we propose to classify the games that used in foreign language lessons (FL), into two main groups:

1. Didactic on-line games, which should include grammatical, lexical, phonetic and spelling games that contribute to the formation of speech skills for students. In contrast to games, in general, didactic online play has an essential feature - a clearly defined goal of teaching and a result corresponding to it, which can be substantiated, singled out in the explicit form and are characterized by educational and cognitive orientation. Through the didactic game, the players have to learn something. The didactic online game is characterized by the following:

- communication with a specific educational goal;

- the ability to repeat, interrupt or start over at any time;

- the opening, the end of the game is not precisely defined;

- adherence to explicit rules that may be changed by players;

- satisfaction from participation, lack of "consequences" for playing (this activity should not be evaluated in any way).

The fundamental difference between didactic on-line games and exercises and tasks of these games are identified that:

Firstly, the on-line game does not have a predetermined pattern of behavior, and the participant himself chooses a possible version of speech interaction and evaluates the result of its implementation. The only limiting factor for the content and form of the game is educational material (lesson topic, goal, planned results).

Secondly, the on-line game is usually adversarial, competitive. The student enter into relationships with partners in the game, evaluates his strengths in comparison with other players. The game allows him to objectively assess his capabilities.

Thirdly, in the on-line game process, students learn interpersonal and group communication, learn to choose the best means solutions (linguistic and non-linguistic) conflict situations. The game forms the ability to correlate their actions with the actions of other players, that is, to cooperate.

G.Heyd divides didactic on-line games used in foreign language classes into two large groups: 1) "games with language material" 2) "games in language" [10]. The first correspond to classes aimed at systematizing the language material. At the same time, much attention is paid to the knowledge of grammar rules. Therefore, such games are well suited not only for training at the beginning, but also for training individual structures at the advanced stage. Games with language material can be fully programmed and controlled. Wagner calls such games "transformed exercises" which are not only playful in nature, but only because of the presence of a competitive element converted into games.

2. On-line creative acting, role-playing is one way interactive teaching foreign languages. Concepts such as role play, simulation, drama and acting are often used interchangeably, but in reality they have different meanings. When simulating students play their natural role, in other words, the role in which they play in real life (for example, the role of a buyer or booking tickets for transport). In role-playing, students play a role that they do not play in real life (for example, prime minister or rock star). In the online role-playing game, participants assign roles that they are played out as part of the script. The simulation focuses on the interaction of one role with others. Anyway, on-line role play prepares students for social interaction in a different social and cultural context. From this on-line play is a very flexible educational activity that has a wide range of possibilities for variety and imagination. In on-line roleplaying games, various communication techniques are widely used, thereby developing fluency in the language, classroom interaction and increased motivation. On-line play improves speaking skills of 
students in any situation, because almost all educational time in the role-playing game is allocated for speech practice, while not only the speaker, but also the listener is as active as possible, so how he should understand and remember the partner's remark, correlate his with the game situation, determine how relevant the situation and the task of communication and respond correctly to it [11].

A wide variety of ICT teaching tools allows to use effectively them in training foreign language. In the practice of our teaching activities, we widely use the created specifics for specific classes with short text in the specialty, basic language formulas, clichés for summarizing and annotating articles and texts in the specialty, etc. Increasing interactivity leads to more intense participation in the learning process of the learner, which contributes to growing the efficiency of perception and memorization of educational material.

Currently, a computer support to teach foreign language course. Without replacing a textbook or other teaching aids, electronic publications have their own didactic functions. The main role is played by using various materials by the instructor. The software includes training and monitoring programs, electronic textbooks. Multimedia tutorials that present clearly the material, provide quick feedback (instant control over the assimilation of the material). Interactive mode allows students themselves control the speed of passing the educational material; the branched structure of hyperlinks allows to get an explanation, additional information [12].

Our observations show that using information-communication technologies increases the efficiency of the educational process, activates the cognitive activity of students. Objective monitoring of progress carried out by the program, completely eliminates bias towards student assessment. The multifaceted possibilities of educational resources of the Internet in educational activities develop creative, research abilities of students, increase their activities, contribute to the acquisition of skills that are very useful in future professional activities. Information technologies create conditions for self-expression of the student's personality: the results of their creativity may be in demand, useful for others.

\section{CONCLUSION AND RECOMMENDATION}

The information-communication technologies can be used effectively for familiarization, training and consolidation of new linguistic knowledge, abilities, skills, as well as at the stage of their control. The usage of modern pedagogical technologies makes it possible to move from learning as a function of memorization to learning as a process of mental development; from a static model of knowledge to a dynamic system of mental actions; from external motivation for learning to internal moral and volitional regulation. Using informational-communication technologies in the process of teaching a foreign language reveals the enormous potential of the computer as an effective teaching tool. Computer training programs allow to train various types of speech activities nd combine them in different combinations, be aware of linguistic phenomena, contribute to the formation of linguistic abilities, create communicative situations, automate language and speech actions, and also ensure the implementation of an individual approach and intensification of independent work of students.

It is necessary that every teacher apply information and communication technologies in the educational process: a computer in the educational process - not a mechanical teacher, a deputy teacher, but an active means of student development, strengthening and expanding the possibilities of his cognitive activity. Computer provides the teacher with the opportunity to free up time for creative activity and create individual educational routes for students.

After examining the state of the problems of using ICT in the field of teaching foreign languages, we can conclude that the effectiveness of the application of usage information and communication technologies. ICT depends on the methods and forms of application of these technologies, on how competently the teacher owns the method of working with them, from the usage them electronic resources. Based on the study theoretical problems of research, analysis of ICT resources and experience in the practical application of data resources in the process of teaching a foreign language, there are a number of recommendations for teachers who use information and communication technologies in their classes:

1. The teacher and the student are able to handle a computer at the level required for performing computer tasks.

2. The teacher should clearly understand what forms of ICT should be used at this stage of the lesson and whether this use is justified.

3. It is necessary to select in advance the material for the lesson using ICT, guided by certain criteria, adapt the selected digital material in accordance with the objectives and conditions of training.

4. The teacher should plan and organize independent work of students in the subject using ICT.

Thus, the usage of ICT tools when teaching a foreign language, it helps to increase the interest of students in the subject and to activate their speech-thinking activity, the development of skills of independent work and work in a team, the effective formation of all types of speech activity. Systematic 
work with computer tasks forms students stable skills of independent work, which leads to a reduction in the time for completing standard tasks and allows to increase the time for performing creative work. The using of information and communication technologies is possible at all levels of education and for various purposes: to provide visibility, building a monologue and dialogue, preparing for the final state certification and others. Technologies in educational activities allows the formation of key competencies of students, to achieve a positive result in the formation of universal educational actions, to implement in practice intercultural communication.

\section{REFERENCES}

1. Eremina T.Yu. The role of educational technologies in achieving meta-subject results of education // Innovative educational technologies as a resource for meta-subject results: Printing House LLC, 2016.- P.4-12

2. Farhodov A.G. Today ICT plays essential role. Tashkent, 2018, 28p

3. Gornakova N.V. Game technologies as a way of competence approach. - URL: http://festival.1september.ru/articles/596556/

4. Koptyug N. M. Internet lessons as auxiliary material for an English teacher // Foreign languages at school. - 2000. - № 4.

5. Levitskaya A.F., Fedorov A.V. The role and importance of web quests in modern education // School technologies. - 2010. № 4

6. March, T. Criteria for Assessing Best Web Quests. 2002-2003. [Electronic resource] - Access mode: http://www.bestwebquests.com/bwq/matrix.asp (date accessed 10.06.19)

7. Masharova T.V., Polushkina G.F. Interactive whiteboard as a means of technology implementation media education. - 2016.№ -3. P30-35.

8. Mikhailenko T.M. Game technologies as a type of pedagogical technologies // Pedagogy: traditions and innovations: materials of the Intern.scientific. conf. (Chelyabinsk, October 2011). - T. I. Chelyabinsk: Two Komsomolets, 2011.-P. 140-146.

9. Nikolaeva N.V. Educational quest projects as a method and means of developing students' skills in informational activity // Issues of Internet education. - 2002. - №7.

10. Novikov A.M., Novikov D.A. Educational project: methodology on educational activities. - M., 2004.

11. Podoprigorova L. A. Using the Internet in teaching foreign languages // Foreign languages at school. 2003. - №5.

12. Polushkina G.F. Assessment of meta-subject results of education in a foreign language in basic school // Scientific-methodical electronic journal "Concept". - 2017. - №V10. - P. 51-55. URL: http://ekoncept.ru/2017/171035.htm.

13. Polushkina G.F. Multimedia simulators as a means of implementing Educational Standard // Management the process of introducing electronic teaching aids into the practice of a modern teacher in conditions for the implementation of the Educational Standard: the collection materials of the creative laboratory participants 04-08 December 2017 / author-comp. Kirov, 2018 .-96 p.

14. Polushkina G.F., Korzunina A.S. Formation of communicative competence of students through implementation of an integrative approach to teaching English // Foreign languages at school. -2017. №8.- P 46-50.

15. Saykov BP Organization of the information space of an educational institution: a practical guide. - M., 2005.

16. The Dictionary of pedagogical usage / ed. L. M. Luzina. - Poskov, 2003.

17. Voitko S. A. On the use of information and communication technologies in English lessons language // Internet magazine Festival of pedagogical ideas "Open lesson", 2004-2005 [Electronic resource].

- URL: http://festival.1september.ru/articles/415914/. 